\title{
Diagnostic problems in biliary duct lymph nodes
}

\author{
GEORGE WILLIAMS AND J. S. WHITTAKER \\ From the Department of Pathology, University of Manchester
}

SYNOPSIS Lymph nodes in the area of the cystic duct are sometimes included with surgically removed gall bladders for pathological examination. These nodes may show a range of histological changes, including sinus histiocytosis and panhyperplasia with, or without giant cell systems, granuloma and fibrosis. The nature and incidence of these changes were studied with appropriate lymph nodes collected routinely from 80 patients, mainly at necropsy. Awareness of these changes should obviate possible serious error in histological diagnosis.

The lymph nodes draining the gall bladder, commonly situated near the cystic and hepatic bile ducts (Fig. 1) are sometimes included in cholecystectomy specimens received for pathological examination. Two or more lymphoid masses, varying in size (up to $2 \mathrm{~cm}$. in diameter) may be present.

The histological appearances of these nodes range from normal through a simple reactive hyperplasia to a more pleomorphic picture in which numerous giant cells and even granulomata may be found. These latter changes in particular may pose a diagnostic problem to anyone unfamiliar with the histological appearances of lymph nodes in this site. Attention has been drawn to this problem in the U.S.A. by Aponte (1960) but we have been unable to find any comparable study in the British literature.

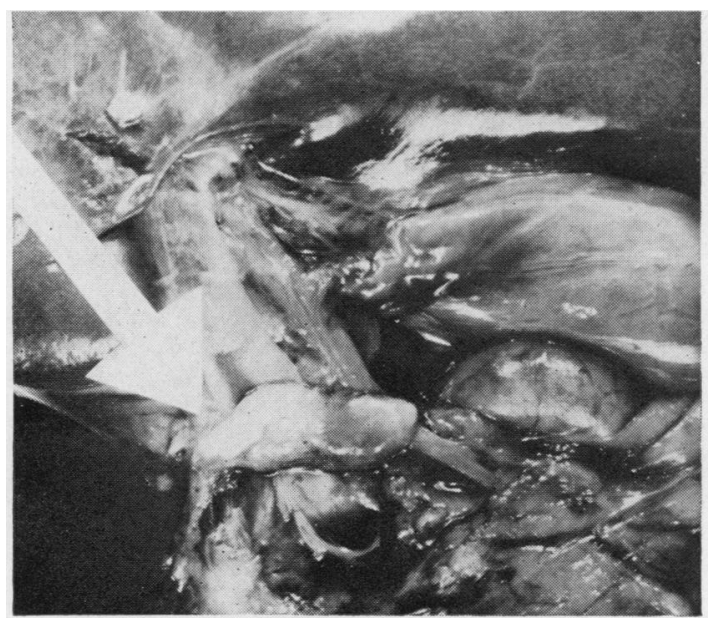

FIG. 1. Enlarged lymph node (arrow) near junction of cystic and hepatic bile ducts.

Received for publication 20 March 1954.
Accordingly, a series of lymph nodes from the cystic duct area was collected from patients at necropsy, or as surgical specimens, with a view to establishing the frequency and nature of these histological changes.

\section{MATERIALS AND METHODS}

Lymph nodes from the area of the cystic duct were examined from 80 patients of ages ranging from 28 to 79 years, 77 being routine necropsy and three biopsy specimens. The only patients excluded from the series were those suffering from a reticulosis of any kind. After fixation in $10 \%$ formalin saturated with mercuric chloride, paraffin sections were stained with haemalum and eosin; specimens fixed in a formalin-cetylpyridinium chloride (C.P.C.) (Williams and Jackson, 1956) were stained by the periodic-acid-Schiff and Hale's colloidal iron techniques for glycoprotein and acid polysaccharides. Formalin-fixed tissue and fresh frozen cryostat sections were also examined for fat content. Sections of gall bladder were also taken from some of the cases. In 14 cases, lymph nodes were simultaneously taken from the para-aortic and deep cervical chains and the axilla for comparison.

\section{RESULTS}

Of the 80 patients studied, 43 had normal lymph nodes; the remaining 37 produced pathological nodes in which sinus histiocytosis, histiocytosis or panhyperplasia accompanied by giant cell systems or granulomata, and fibrosis, were the principal abnormalities. The incidence of these changes is seen in Table $\mathbf{I}$.

\section{NATURE OF THE HISTOLOGICAL CHANGES}

GROUP I: NODES SHOWING SINUS HISTIOCYTOSIS This was the largest group showing abnormal nodes. 
TABLE I

INCIDENCE OF LYMPH NODE LESIONS

\begin{tabular}{|c|c|c|c|}
\hline Histology & Group & \multicolumn{2}{|c|}{ No. of Cases } \\
\hline $\begin{array}{l}\text { Normal } \\
\text { Sinus histiocytosis }\end{array}$ & $\bar{I}$ & & $\begin{array}{l}43(54.0 \%) \\
22(27.5 \%)\end{array}$ \\
\hline Sinus histiocytosis with granulomata & & 1 & ) \\
\hline $\begin{array}{l}\text { Sinus histiocytosis with giant cells } \\
\text { Panhyperplasia with giant cells }\end{array}$ & & $\begin{array}{c}10 \\
2\end{array}$ & $13(16.0 \%)$ \\
\hline $\begin{array}{l}\text { Fibrosis } \\
\text { Totals }\end{array}$ & III & & $\begin{array}{c}2(2.5 \%) \\
80(100 \%)\end{array}$ \\
\hline
\end{tabular}

Their main feature was a hyperplasia of histiocytes (Fig. 2), some containing fine lipid droplets lining dilated sinusoids; plasma cell and lymphoid hyperplasia were not pronounced; nine nodes $(41 \%)$ of this group contained prominent pigment deposits distributed both in macrophages and extracellularly. Some of this pigment, mainly the intracellular form, reacted histochemically for iron; the non-ironcontaining pigment was P.A.S.-negative, non-acidfast, and therefore probably not ceroid. Stains for bile pigment, including methylene blue, Stein's iodine-thiosulphate, and Fouchet's reagent (Hall, 1960) were also negative. A positive reaction was obtained, however, with Sudan Black (Fig. 3).

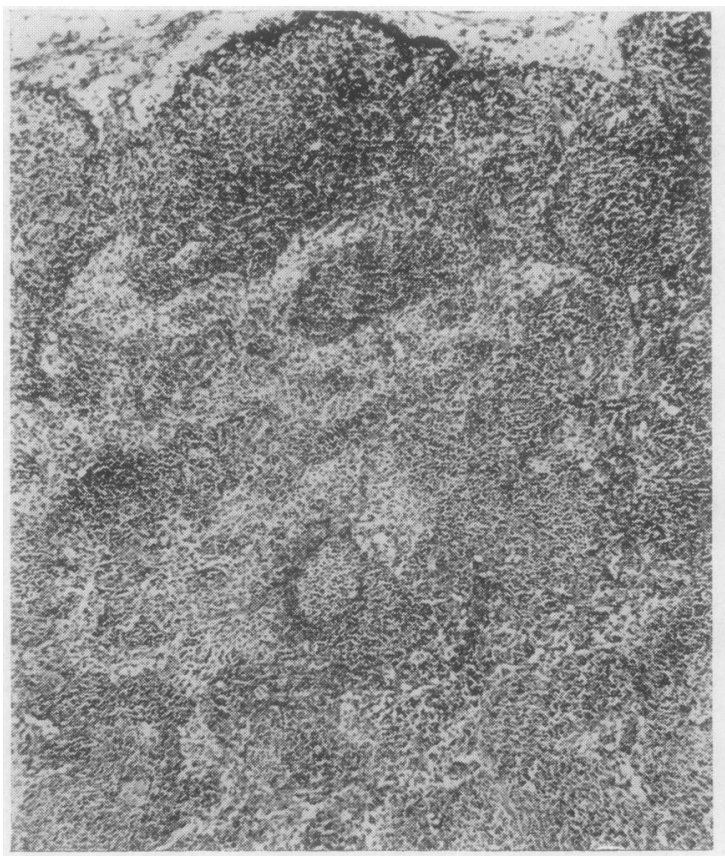

FIG. 2

FIG. 2. Lymph node showing proliferation of histiocytes within dilated sinusoids. Haemalum and eosin $\times 55$.

FIG. 3. Pigment deposits (arrow) associated with fat globules in lymph node macrophages. Sudan black and neutral red $\times 400$.
GROUP II: NODES SHOWING GIANT CELLS The histological appearances of this group were interest ing and striking. Giant cells were prominent and ofen two distinct types, one multinucleated with foamyo cytoplasm containing lipid and sometimes pigment $\overline{\text { v }}$ occurring singly or as aggregates around fattyos globules (Fig. 4). Sinus histiocytosis similar to thato in group I nodes was a feature of this group. The other form of giant cell was mononucleated with ${ }^{\text {s }}$ densely aggregated nuclear chromatin and baso- 0 philic or clear, lipid-free cytoplasm (Fig. 5). These $\overrightarrow{-}$ were particularly prominent in two surgicallyo nodes.

Granulomata, composed of large, pale macro $-\overrightarrow{0}$ phage epithelioid cells, were present in a third surgical specimen (Fig. 6) in conjunction with sinus histiocytosis. Eosinophil leucocytes were also featured prominently in three nodes in this group.

GROUP III: NODES SHOWING FIBROSIS Although only two in number, the specimens are grouped separ $₹$ ately on account of their extensive fibrosis, presum- $\overrightarrow{-}$ ably of post-inflammatory type in the absence of other significant changes.

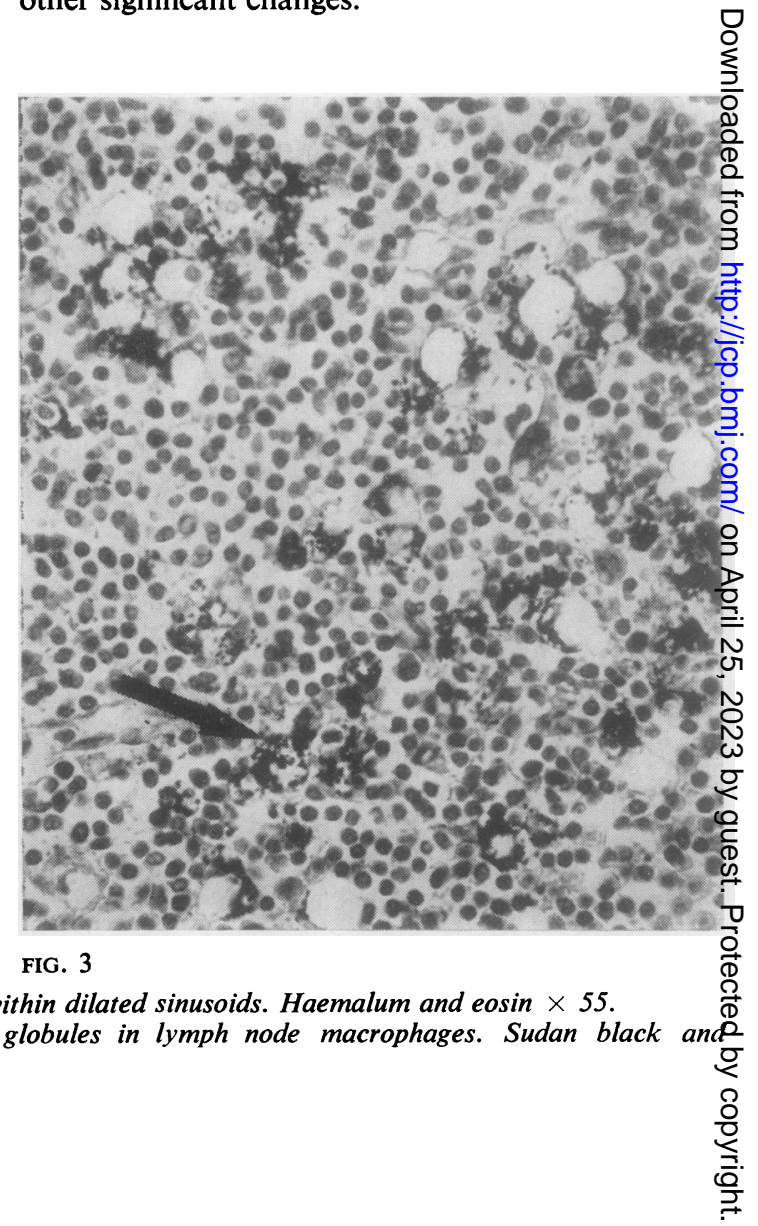
removed specimens showing panhyperplasia of the 


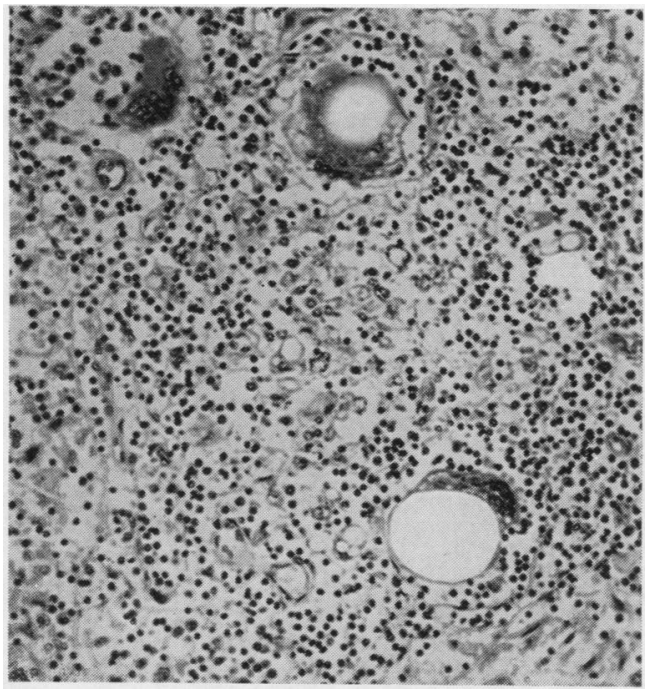

FIG. 4. Multinucleated lipid-laden giant cells and smaller macrophages. Haemalum and eosin $\times 200$.

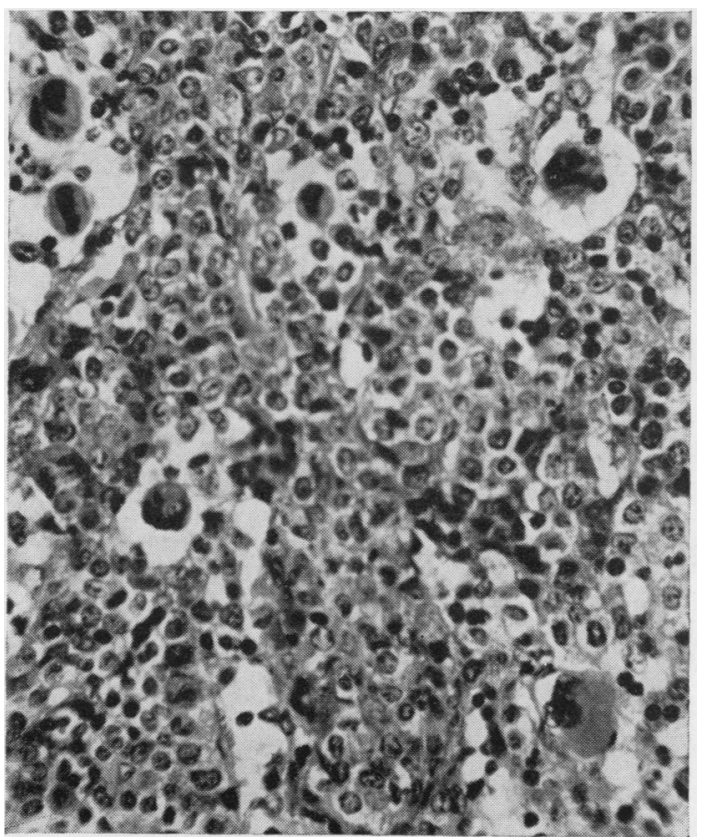

FIG. 5. Mononucleated giant reticulum cells as part of lymph node panhyperplasia. Haemalum and eosin $\times 450$.

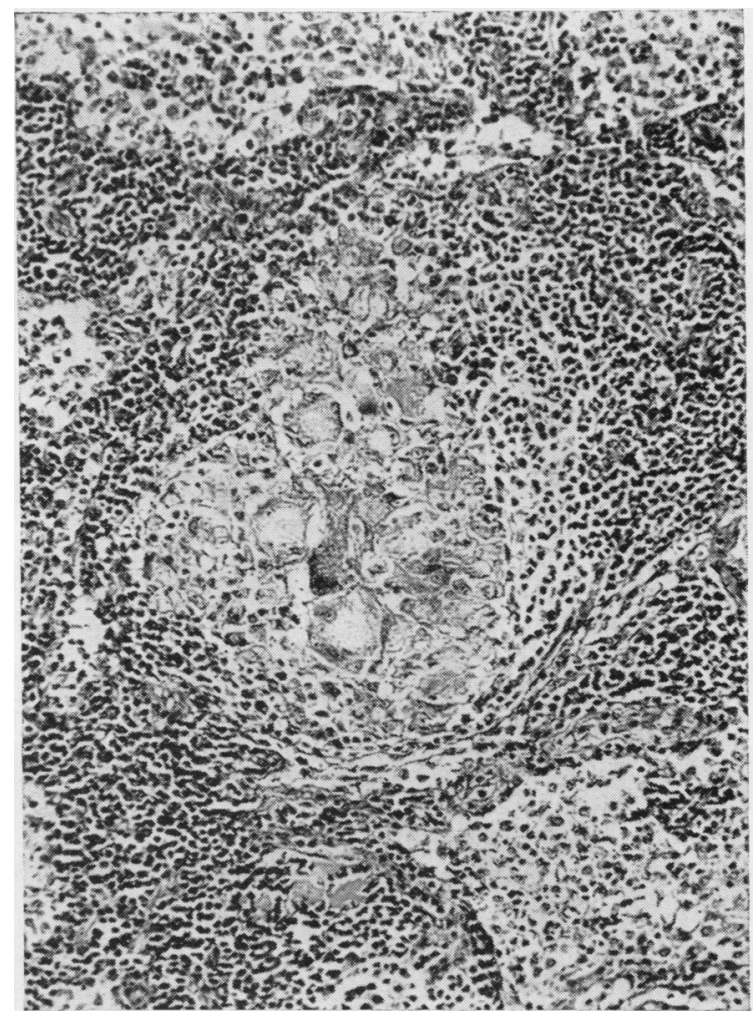

FIG. 6. Granuloma formed of pale epithelioid macrophages. P.A.S./haematoxylin $\times 250$. 


\section{DISCUSSION}

Sinus histiocytosis, the most common feature of the pathological nodes, was the sole lesion in $27.5 \%$ of cases, and associated with giant cell systems or granulomata in a further $14 \%$ of cases. According to Marshall (1956), sinus histiocytosis represents a hyperplasia of macrophages in nodes draining foci of tissue damage. In the present context it reflects the frequency of gall bladder disease, although a correlation between the two was prevented by the autolytic changes in most of the gall bladder specimens obtained at necropsy. Lymph node panhyperplasia involving the formation of secondary reaction centres, plasma cell proliferation in the medullary cords as well as hyperplasia of sinus histiocytes, was present in only two specimens of the series removed surgically in conjunction with gall bladders showing active chronic inflammatory changes.

The most striking histological feature of the whole series was the presence of giant cells (group II).

Multinucleated forms of macrophage type were invariably associated with hyperplasia of sinus histiocytes from which in all likelihood they were derived by fusion. Many contained lipid or were associated with large extracellular lipid droplets. In one case, as Touton giant cells, they featured in multiple granulomata. Pigment deposits were present in less than half of the nodes of this group, indicating that lipid was the main stimulus to the formation of this type of giant cell. The other giant cell form, mononucleated and lipid-free, was regarded as a primitive reticulum cell formed as part of a lymph node panhyperplasia in response active gall bladder inflammation. In one instance they were sufficiently numerous to suggest reticulosis; none, however, showed mirror-imase nuclear forms and the remainder of the noc structure indicated a brisk reactive hyperplasia.

The macroscopic green or brown deposits group II nodes were most likely of bile origie Failure to confirm this by various histochemicál methods may have been due to complexing of the bile pigment with lipid as indicated by an affinity for Sudan Black and to a lesser extent for Sudan IV.

In 14 of the cases, three of which showed pres minent histiocytosis and giant cell systems, lymph nodes taken from the deep cervical, axillary, anep para-aortic regions for comparison showed normat appearances.

The lymph node changes described in this series indicate the range of histological variation whicht may affect lymph nodes in this region. As such they are regarded essentially as local phenomena and of a reactive nature. Appreciation of these points wouf serve to avoid serious errors in histological interpret ation.

We are indebted to Messrs N. Mowat, J. T. Stopfor and G. Saville for help with photography and the histological preparations.

\section{REFERENCES}

Aponte, G. E. (1960). Amer. J. clin. Path., 34, 57.

Hall, M. J. (1960). Ibid., 34, 313.

Marshall, A. H. E. (1956). An Outline of the Cytology and Pathology of the Reticular Tissue. Oliver and Boyd, Edinburgh.

Williams, G., and Jackson, D. S. (1956). Stain. Technol., 31, 189. 